\title{
Pengaruh Iklan terhadap Minat Beli Pengguna Youtube dengan Brand Recognition sebagai Variabel Intervening
}

\author{
Herdian Rizky Yuniyanto ${ }^{1}$, Hani Sirine ${ }^{2}$ \\ Universitas Kristen Satya Wacana \\ 1'hherdian.rizki@gmail.com, 2hani.sirine@staff.uksw.edu
}

\begin{abstract}
Internet media can be used to do marketing, one of which is Youtube. This study aims to explain the effect of advertising on buying interest on Youtube users using brand recognition as an intervening variable. The sample in this study amounted 180 students of Universitas Kristen Satya Wacana who saw Nike product advertising on Youtube. The analysis technique used is path analysis. The result of the research shows that advertising have a significant positive effect to brand recognition, brand recognition have significant positive effect to buying interest, and brand recognition can not function as intervening variable in relationship between advertising and buying interest.
\end{abstract}

Keywords: consumer behavior, advertising, brand recognition

\begin{abstract}
Abstrak
Media internet dapat digunakan untuk melakukan pemasaran, salah satunya adalah Youtube. Penelitian ini bertujuan untuk menjelaskan pengaruh iklan terhadap minat beli pada pengguna Youtube dengan menggunakan brand recognition sebagai variabel intervening. Sampel dalam penelitian ini berjumlah 180 mahasiswa UKSW yang melihat iklan produk Nike di Youtube. Teknik analisis yang digunakan adalah analisis jalur. Hasil penelitian menunjukkan bahwa iklan berpengaruh positif signifikan terhadap brand recognition, brand recognition berpengaruh positif signifikan terhadap minat beli, dan brand recognition tidak mampu berfungsi sebagai variabel intervening dalam hubungan antara iklan dan minat beli.
\end{abstract}

Kata kunci: perilaku konsumen, iklan, brand recognition

\section{Cara Mengutip:}

Yuniyanto, H. R., \& Sirine, H. (2018). Pengaruh Iklan Terhadap Minat Beli Pengguna Youtube Dengan Brand Recognition sebagai Variabel Intervening. Esensi: Jurnal Bisnis dan Manajemen. Vol. 8 (1): 21 - 28. doi: 10.15408/ess.v8i1.5885. 


\section{PENDAHULUAN}

Iklan merupakan pesan suatu merek, produk, atau perusahaan yang disampaikan kepada audiens melalui media. Pemilihan media dalam periklanan harus dilakukan secara tepat, salah satunya melalui media internet (Paramitadewi, 2009). Hadirnya internet dapat mendukung efisien dan efektifitas perusahaan, terutama sebagai sarana komunikasi, publikasi, serta sarana untuk mendapatkan berbagai informasi yang dibutuhkan oleh sebuah badan usaha (Ditya, 2015).

Penggunaan media internet memudahkan memperoleh informasi yang dibutuhkan. Menurut Asosiasi Penyelenggara Jasa Internet Indonesia (APJII) jumlah pengguna internet di Indonesia mencapai 97, 4\% (APJII, 2016). Ada banyak media sosial yang sekarang ini digunakan oleh masyarakat di seluruh dunia, salah satunya Youtube, yang merupakan salah satu media sosial terpopuler di Indonesia bahkan di dunia selain Facebook dan Twitter. Situs analisis Socialbakers (2016) menunjukkan bahwa Indonesia berada di peringkat ke-4 sebagai negara pengguna Youtube di dunia. Menurut APJII, penggunaan Youtube masuk peringkat ke-3 dibandingkan facebook dan instagram yaitu sebesar $11 \%$ atau 14, 5 juta jiwa.

Youtube mempunyai lebih dari satu miliar pengguna, Hampir sepertiga dari semua pengguna internet menonton video di Youtube dan menghasilkan miliaran kali penayangan. Jumlah jam yang diluangkan orang-orang untuk menonton video di Youtube naik $60 \%$ per tahunnya, dan merupakan pertumbuhan terpesat dalam kurun waktu 2 tahun terakhir. Jumlah pengiklan yang menjalankan iklan video di Youtube naik hingga lebih dari $40 \%$ per tahun.

Sementara Gale Business Insights Essential (2014) menyatakan bahwa Nike adalah perusahaan sepatu olah raga dengan revenue tertinggi dibanding dengan perusahaan lainnya seperti Adidas, Reebock, Puma dan New balanced. Adapun grafik revenue dapat dilihat pada Gambar 1. Di antara banyak merek sepatu olahraga, produk Nike sukses menjadi produk dengan penjualan tertinggi. Hal tersebut dapat dilihat pada Tabel 1.

Tabel 1. Nilai Penjualan Beberapa Merek Sepatu Tahun 2014 (dalam Juta US\$)

\begin{tabular}{cccc}
\hline Peringkat & Merek & Nilai penjualan & Market share \\
\hline 1 & Nike & 13.364 & $36.4 \%$ \\
2 & Adidas & 6.804 & $18.6 \%$ \\
3 & Sketch & 2.007 & $5.5 \%$ \\
4 & Asix & 1.994 & $5.4 \%$ \\
5 & Puma & 1.887 & $5.1 \%$ \\
\hline
\end{tabular}

Sumber: http://inatrims.kemendag.go.id/ (2016)

Untuk pelanggan di Indonesia, merek sepatu Nike mendapatkan peringkat kedua setelah Bata (Top Brand, 2016), hal ini bisa dilihat pada Tabel 2. Data tersebut didukung dari pretest yang dilakukan peneliti kepada 100 mahasiswa Universitas Kristen Satya Wacana pada tanggal 12 Oktober 2016. Dari pretest tersebut diperoleh hasil sebagai berikut: mahasiswa yang memperhatikan iklan produk Nike di Youtube sebesar 71\% dan mahasiswa yang tidak memperhatikan iklan di Youtube sebesar 29\%. Mereka juga menyatakan bahwa 
74\% tertarik membeli setelah melihat iklan di Youtube, dan 93\% tertarik membeli karena mereka mengetahui dan mengenal produk Nike.

Chuan Chu, dkk (2008) menjelaskan bahwa iklan bisa membentuk persepsi konsumen saat akan memilih suatu produk atau merek. Faktor-faktor seperti informative, entertaining, societal, dan economic digunakan sebagai pembentuk sikap terhadap iklan yang pada akhirnya akan berpengaruh pada sikap terhadap merek. Kurniawati (2009) menambahkan bahwa iklan dapat diukur melalui informasi atau pengetahuan tentang produk, adanya daya tarik bagi konsumen, nilai inovasi, keterjangkauan dan pemenuhan kebutuhan pengguna.

Tabel 2. Top Brand Tahun 2016 di Indonesia

\begin{tabular}{ccc}
\hline MEREK & TBI & TOP \\
\hline Bata & $27.1 \%$ & TOP \\
Nike & $18.1 \%$ & TOP \\
Converse/All star & $17 \%$ & TOP \\
Adidas & $5.4 \%$ & \\
Kasogi & $5.3 \%$ & \\
Dallas & $3.9 \%$ & \\
\hline
\end{tabular}

Sumber : www.topbrand.com (2016)

Hasil penelitian Spears dan Singh (2004), Suwito (2007), Arista (2011), Mufarihah \& Triyono (2013), Gunawan \& Dharmayanti (2014), Purnamasari (2016), Adinata (2016), dan Herdaningtyas \& Iriani (2017) menyatakan bahwa iklan berpengaruh positif siginifikan terhadap minat beli. Schiffman \& Kanuk (2004) mendefinisikan minat beli sebagai suatu sikap senang terhadap suatu objek yang membuat individu berusaha membayar atau berkorban untuk mendapatkan objek tersebut. Sementara hasil penelitian Setyawan (2015) menyatakan bahwa brand recognition berpengaruh terhadap minat beli.

Brand Recognition merupakan tingkat di mana ingatan konsumen terhadap suatu merek akan muncul jika konsumen melihat iklan dari media promosi (Simanjuntak, 2004). Brand Recognition adalah salah satu pembentuk brand awareness dan merupakan tingkatan awal konsumen menyadari sebuah merek (Durianto dkk, 2001). Penelitian Pasharibu dkk. (2013) menempatkan brand recognition sebagai variabel intervening antara variabel iklan dengan minat beli dengan unit amatan pengguna jejaring sosial. Oleh karena itu penelitian ini hendak menguji kembali penelitian Pasharib, dkk (2013) dengan unit amatan pengguna Youtube yang telah melihat iklan produk Nike.

Adapun tujuan penelitian ini adalah: pertama, untuk menjelaskan pengaruh iklan terhadap brand recognition pada pengguna Youtube yang melihat iklan produk Nike. Kedua, untuk menjelaskan pengaruh brand recognition terhadap minat beli pada pengguna Youtube yang melihat iklan produk Nike. Ketiga, untuk menjelaskan pengaruh iklan terhadap minat beli pada pengguna Youtube yang melihat iklan produk Nike dengan menggunakan brand recognition sebagai intervening variable. 
Hasil penelitian ini diharapkan dapat memberi kontribusi bagi pemasang iklan produk Nike yaitu perlunya mempertimbangkan brand recognition yang berkaitan dengan minat beli konsumen. Sedangkan bagi Youtube, hasil penelitian ini dapat menjadi pertimbangan untuk membuat kolaborasi yang efektif dengan pemasang iklan produk Nike sehingga menghasilkan win-win situation.

\section{METODE}

Populasi penelitian ini adalah mahasiwa Universitas Kristen Satya Wacana. Sampel diperoleh dengan purposive sampling yang mana kriteria responden adalah pengguna Youtube yang melihat iklan produk Nike. Adapun kuesioner yang disebarkan berjumlah 200 kuesioner, namun hanya 180 kuesioner yang diolah dalam penelitian ini karena 20 kuesioner tidak terisi lengkap. Kuesioner diedarkan di Universitas Kristen Satya Wacana dari tanggal 15 November sampai 23 November 2016. Metode analisis yang dipergunakan dalam penelitian ini ialah analisis lajur (path analysis). Penggunaan analisis lajur dikarenakan adanya variabel intervening yang dipergunakan dalam model penelitian ini.

\section{HASIL DAN PEMBAHASAN}

Analisis regresi linier sederhana digunakan untuk menguji pengaruh iklan terhadap brand recognition. Hasil olah data dapat dilihat pada Tabel 3 . Nilai $t_{\text {hitung }}$ variabel iklan adalah sebesar 3.955 dan nilai $t_{\text {tabel }}$ pada tingkat signifikansi $1 \%(\alpha=0.01)$ dan degree of freedom $(\mathrm{n}-2)=178$ yang diperoleh dengan ketentuan $\mathrm{t}_{\text {tabel }}$ signifikansi $0,01 / 2=0.005$ adalah sebesar 2.60373. Keputusannya nilai $t_{\text {hitung }}(3.955)>t_{\text {tabel }}(2.60373)$ sehingga brand recognition dipengaruhi oleh iklan dengan persamaan matematis sebagai berikut: Brand Recogniton = 7.285+ 0.133 Iklan. Hal tersebut berarti iklan berpengaruh positif signifikan terhadap brand recognition. Adapun hasil Adjusted $R$ Square diperoleh sebesar 0.076 artinya presentase sumbangan pengaruh variabel iklan terhadap brand recognition sebesar 7.6\%.

Tabel 3. Pengaruh Iklan terhadap Brand Recognition

\begin{tabular}{c|c|c|c}
\hline Model & Coefficients & t-value & Signifikansi \\
\hline (Constant) & 7.285 & 7.421 & 0.000 \\
Iklan $(X)$ & 0.133 & 3.955 & 0.000 \\
\hline \multicolumn{3}{c}{ Sumber: Data Primer yang Diolah, 2016 }
\end{tabular}

Hasil tersebut menunjukkan bahwa iklan produk Nike di Youtube memiliki kontribusi dalam meningkatkan brand recognition. Hal ini sejalan dengan penelitian Pasharibu dkk (2013) yang menjelaskan adanya pengaruh iklan terhadap brand recognition melalui jejaring sosial dan mendukung penelitian Ditya (2005) yang menyatakan bahwa melalui media Youtube, iklan sebuah produk akan menjadi lebih efektif. Iklan produk Nike sering muncul pada saat menonton video di Youtube sehingga menguatkan merek Nike pada ingatan pengguna.

Untuk mengidentifikasi pengaruh brand recognition terhadap minat beli juga digunakan analisis regresi linier sederhana. Hasil olah data dapat dilihat pada Tabel 4. 
Pada kolom $t$ terdapat nilai $t_{\text {hitung }}$ variabel brand recognition adalah sebesar 3.739 dan nilai $t_{\text {tabel }}$ sebesar 2.60373. Nilai $t_{\text {hitung }}(3.739)>t_{\text {tabel }}$ (2.60373) sehingga variabel minat beli dipengaruhi oleh brand recognition dengan persamaan matematis sebagai berikut: Minat Beli $=13.283+0.407$ Brand Recognition. Hal ini berarti brand recognition berpengaruh positif signifikan terhadap minat beli. Adapun nilai Adjusted $R$ Square yang diperoleh sebesar 0.068 artinya presentase sumbangan pengaruh variabel brand recognition terhadap minat beli sebesar $6.8 \%$.

Tabel 4. Pengaruh Brand Recogniton terhadap Minat Beli

\begin{tabular}{cccc}
\hline Model & Coefficients & t-value & Signifikansi \\
\hline (Constant) & 13.283 & 10.803 & 0.000 \\
Brand Recognition (Z) & 0.407 & 3.739 & 0.000 \\
\hline
\end{tabular}

Sumber: Data Primer yang Diolah, 2016

Hasil penelitian ini sejalan dengan penelitian Pasharibu \& Purwati (2013) dan Setyawan (2015) yang menyatakan brand recogniton berpengaruh positif signifikan terhadap minat beli. Menurut responden, merek Nike dikenal dengan baik oleh pengguna Youtube dan menimbulkan ketertarikan untuk membeli.

Untuk menguji ada tidaknya peran brand recognition sebagai variabel intervening dalam hubungan antara iklan dengan minat beli maka digunakan metode analisis jalur (path analysis) seperti terlihat pada Gambar 2.

\section{Gambar 1. Analisis Jalur atau Path Analysis}

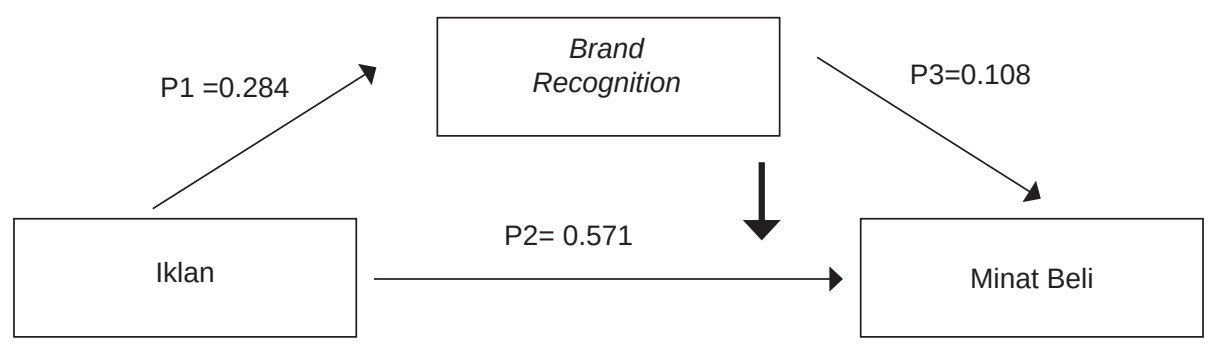

Untuk jalur P1, nilai koefisien standardized beta iklan sebesar 0.284 dengan signifikansi 0.000. Sedangkan untuk jalur P2, nilai koefisien standardized beta untuk iklan sebesar 0.571 dengan signifikansi 0.000 dan untuk jalur P3, nilai koefisien standardized beta untuk brand recognition sebesar 0.108 dengan signifikansi 0.085 . Hal tersebut juga dapat dilihat pada Tabel 5 .

Tabel 5. Peran Brand Recognition sebagai Variabel Intervening

\begin{tabular}{cccc}
\hline Model & Coefficients & t-value & Signifikansi \\
\hline (Constant) & 4.369 & 3.112 & 0.002 \\
Iklan (X) & 0.571 & 9.187 & 0.000 \\
Brand Recognition (Z) & 0.108 & 1.732 & 0.085 \\
\hline
\end{tabular}

Sumber: Data Primer yang Diolah, 2016 
Hasil analisis jalur (path analysis) di atas menunjukkan bahwa iklan dapat berpengaruh langsung terhadap minat beli dengan nilai sebesar 0.571. Sedangkan besarnya pengaruh tidak langsung dapat dihitung dengan mengalikan P1 dan P3 yaitu (0.284) x $(0.108)=0.030672$. Hasil perbandingan nilai pengaruh tidak langsung (yang menggunakan variabel brand recognition sebagai variabel intervening) dengan nilai pengaruh langsung (iklan terhadap minat beli) menunjukkan bahwa nilai pengaruh tidak langsung sebesar 0.030672 , lebih kecil dari nilai pengaruh langsung yaitu sebesar 0.571. Dengan demikian variabel brand recognition tidak berfungsi sebagai variabel intervening pada hubungan antara iklan dan minat beli. Pengujian tersebut juga didukung dengan menggunakan Sobel Test pada Tabel 6. Oleh karena $t_{\text {hitung }}=1.57712654$ lebih kecil dari $t_{\text {tabel }}$ yaitu sebesar 2.60373, maka dapat disimpulkan bahwa koefisien mediasi tidak signifikan. Hal ini berarti brand recognition tidak mampu memediasi atau menjadi variabel intervening dalam hubungan antara iklan terhadap minat beli.

Tabel 6. Sobel Test

\begin{tabular}{cccc}
\hline Keterangan & Test Statistic & Standar Error & P Value \\
\hline Sobel Test & 1.57712654 & 0.01366155 & 0.11476641 \\
Aroian Test & 1.53566401 & 0.01403041 & 0.12462081 \\
Goodman Test & 1.62213969 & 0.01328246 & 0.10477344 \\
\hline
\end{tabular}

Sumber: Data Primer yang Diolah, 2016

Hasil penelitian ini menunjukkan iklan berpengaruh langsung terhadap minat beli. Penemuan ini didukung oleh penelitian Spears \& Singh (2004), Suwito (2007), Arista (2011), Mufarihah \& Triyono (2013), Gunawan \& Dharmayanti (2014), Purnamasari (2016), Adinata (2016), dan Herdaningtyas \& Iriani (2017). Hasil ini diperkuat dengan pretest yang telah dilakukan peneliti yaitu $74 \%$ pengguna Youtube tertarik membeli produk setelah melihat iklan. Hasil penelitian ini juga mendukung pendapat Siswanto (2011) yang menyatakan bahwa media sosial memiliki peluang atau potensi sebagai media beriklan dan pemasaran yang efektif. Usvita (2013) juga menambahkan bahwa semakin tinggi intensitas melihat iklan maka intensitas membeli akan semakin tinggi.

Penelitian ini sejalan dengan penelitian Pasharibu. dkk (2013) yang menjelaskan adanya pengaruh iklan terhadap brand recognition dan mendukung penelitian Ditya (2005) yang menyatakan bahwa melalui media Youtube, iklan sebuah produk akan menjadi lebih efektif. Penelitian Pasharibu, dkk (2013) dan Setyawan (2015) yang menyatakan brand recogniton berpengaruh positif signifikan terhadap minat beli juga sesuai dengan hasil penelitian ini. Spears \& Singh (2004), Suwito (2007), Arista (2011), Mufarihah \& Triyono (2013), Gunawan \& Dharmayanti (2014), Purnamasari (2016), Adinata (2016), dan Herdaningtyas \& Iriani (2017) menghasilkan temuan bahwa iklan berpengaruh langsung terhadap minat beli, sehingga penelitian ini mendukung hasil penelitian mereka. 


\section{SIMPULAN}

Hasil penelitian menunjukan bahwa: pertama, iklan berpengaruh positif signifikan terhadap brand recognition. Kedua, brand recognition berpengaruh positif signifikan terhadap minat beli. Ketiga, brand recognition tidak mampu berperan sebagai variabel intervening dalam hubungan antara iklan dan minat beli. Saran dari penelitian ini adalah pemasang iklan di Youtube harus membuat iklan yang memperkuat merek produk mereka di benak konsumen sehingga menarik minat konsumen untuk melakukan pembelian. Misalnya dengan menambah pengetahuan tentang produk dan inovasi dalam beriklan.

\section{PUSTAKA ACUAN}

Adinata, J. (2016). Pengaruh Periklanan terhadap Minat Beli Konsumen PT. Tokopedia. (Skripsi Tidak Dipublikasikan). Bandung: Universitas Kristen Maranatha.

Arista, E. D. (2011). Analisis Pengaruh Iklan, Brand Trust, dan Brand Image terhadap Minat Beli Konsumen Telkom Speedy di Kota Semarang. (Skripsi Tidak Dipublikasikan). Semarang: Universitas Diponegoro.

Chuan Chu, S., Huang, S., Logan, K., \& Daugherty, T. (2008). Understanding Consumer Perceptions of Advertising: A Theoretical Framework of Attitude and Confidence. Conference American Academy of Advertising, San Fransisco.

Ditya, E. D. (2015). Anteseden Efektivitas Iklan Pop-up di Media Sosial Youtube, (Tesis Tidak Dipublikasikan). Yogyakarta: Universitas Atma Jaya Yogyakarta.

Gunawan, F. A. \& Dharmayanti, D. (2014). Analisis Pengaruh Iklan Televisi dan Endorser terhadap Purchase Intention Pond's Men dengan Brand Awareness sebagai Variabel Intervening. Jurnal Manajemen Pemasaran Petra. Vol. 2 (1): 1-14.

Herdaningtyas, G. \& Iriani, F. (2017). Pengaruh Iklan dan Penggunaan Selebritas dalam Iklan terhadap Minat Beli Produk Melalui Kesadaran Merek sebagai Variabel Intervening. Prosiding Seminar Nasional Ekonomi dan Bisnis (SNEBIS), Fakultas Ekonomi, Universitas Krisnadwipayana.

Mufarihah, H. \& Triyono. (2013). Dampak Periklanan terhadap Minat Beli pada HP Samsung Galaxy (Studi Eksplorasi Pengguna HP Samsung Galaxy di Semarang). (Skripsi Tidak Dipublikasikan). Semarang: Universitas Muhammadiyah Semarang.

Paramitadewi, Y. H. (2009). Pengukuran Kesadaran Merek (Brand Awareness) pada Produk Madurasa PT. Air Mancur Surakarta. (Skripsi Tidak Dipublikasikan). Surakarta: Universitas Sebelas Maret.

Kurniawati, D. (2013). Studi Tentang Sikap Terhadap Merek Dan Implikasinya Pada Minat Beli Ulang, (Skripsi Tidak Dipublikasikan). Semarang: Universitas Diponegoro.

Pasharibu, Y., Purwati, Y., \& Jie, F. (2013), The Influence of Attitude and brand Recognition Toward Purchase Intention of Online Advertising on Social Networking Sites, Proceedings of the18th Asia Pacific DSI Conference, 9-13 July, Bali, Indonesia.

Purnamasari, I. M. (2016). Pengaruh Kemasan Terbaru Susu Kental Manis Frisian Flag dan Daya Tarik Iklan terhadap Minat Beli Konsumen pada Masyarakat Semarang (Studi Kasus pada Masyarakat Semarang Timur). (Skripsi Tidak Dipublikasikan). Semarang: Universitas Islam Sultan Agung. 
Schiffman, L. G., \& Kanuk, L. L. (2008). Perilaku Konsumen, Edisi 7, Jakarta: Indeks.

Setyawan, M. (2015). Pengaruh Brand Recognition, Attitude, dan Confidence terhadap Minat Beli Konsumen pada Layanan Online Traveloka (Studi Kasus pada Mahasiswa Univeristas Brawijaya Malang). Jurnal Ilmiah Mahasiswa FEB Universitas Brawijaya, Vol. 4 (2): 151-160.

Simanjuntak, T. (2004). Strategi Menaklukkan Pasar Melalui Riset Ekuitas dan Perilaku Konsumen, Jakarta: PT. Gramedia Pustaka Utama.

Spears, N. \& Singh S. N. (2004). Measuring Attitude toward The Brand and Purchase Intentions. Journal of Current Issues \& Research in Advertising (CTC Press). Vol. 26 (2): 53-62.

Suwito, A. (2007). Pengaruh Sikap terhadap Merek dan Sikap terhadap Iklan pada Minat Beli Konsumen. (Skripsi Tidak Dipublikasikan). Surakarta: Universitas Muhammadiyah Surakarta. 